\title{
The importance of OER in engineering education
}

\author{
Carmen Sonia Duse ${ }^{1, *}$, Dan Maniu Duse ${ }^{2}$, and Philip Bonnano ${ }^{3}$ \\ ${ }^{1}$ Lucian Blaga University of Sibiu, Department for Teacher Training, Calea Dumbravii nr. 34, Sibiu, \\ Romania \\ ${ }^{2}$ Lucian Blaga University of Sibiu, Engineering Faculty, Department of Industrial Machines and \\ Equipment, Emil Cioran 4, Sibiu, Romania \\ ${ }^{3}$ University of Malta, Faculty of Education, Msida, Malta
}

\begin{abstract}
The problem of education is a very important one and occupies an increasingly wider register among educational specialists, who see these changes directly related to current generations of students. It speaks increasingly more and more about the desire of young people to learn when they want, how they want and how much they want, in their own way, without any constraints imposed by fixed educational program, established by teachers, according to their idea how to go on an educational route. In this context, open education provides crucial support of any person who is interested, and covered a complete and appropriate educational needs, in connection with time and availability of the person. The paper aims to bring attention to the problem of open education and open learning resources, in the context of aligning the educational system at European and world requirements regarding accessibility of education. Also, we use work experience resulting from Erasmus + project entitled "EU-store" European Standards for Open Educational Resources, project no. 2014-1RO01-KA202-002985, project leaded by our university.
\end{abstract}

\section{What are OER}

\subsection{OER Definitions}

The concept of Open Educational Resources was defined for the first time in 2002, within a UNESCO meeting in Paris. Open Educational Resources (OER) are materials for learning, teaching, research or other educational purposes that can be used, adapted and redistributed freely, without constraints - or with very few constraints - related to copyrights. Such materials can be courses, lesson plans, presentations, books, handbooks, homework, questionnaires, activities for the classroom or for the laboratory, games, simulations, tests, audio or video resources and many more, available in digital format or on a physical support, to which the access is free.

\footnotetext{
*Corresponding author: carmen.duse@ulbsibiu.ro
} 
Open Resources are resources to which the access is free or for a moderate fee, from anywhere in the world and from any type of platform - from the computer, from the table or from the phone. However, OER are not only digital resources or those associated with eLearning. OER can also be resources in physical, printed format.

In order to be called open educational resources, they must be free or have a reduced cost, to not have a commercial purpose, to be accessible from anywhere in the world and with any type of technology and, moreover, to have a free license. However, this is not an universally accepted point of view and there exist several definitions for Open Educational Resources. For example, in the definition adopted by UNESCO there is comprised also the part of free licensing, whereas OER Commons does not mention the type of license that resources need to have.

The first question which can arrive is where to find these OER and the second one is how free these are? A complete and certain list of all OER initiatives and databases is impossible, given their dynamic nature. Thus, even if the number of freely available documents increases daily, the finding of documents of interest remains a task for the user. On the other hand, there is very much need to be checked the license under they are published.

The most important universities are developing OER concerned on a variety of subjects for learning and development. There are a lot of other OER websites for people with small budgets and no formal training in education, especially at higher levels. The aim is to make these courses accessible, to share knowledge and therefore to make society more performant and tolerant through learning and development.

In point $\mathrm{A}$ of the Paris OER Declaration are presented Open Educational Resources as an important step in education, this Declaration recommends to: "Promote and use OER to widen access to education at all levels, both formal and non-formal, in a perspective of lifelong learning, thus contributing to social inclusion, gender equity and special needs education. Improve both cost-efficiency and quality of teaching and learning outcomes through greater use of OER" (UNESCO 2012).

A resource is considered educational if, as Camilleri, Ehlers, \& Pawlowski [1] said:

"- it has been produced / released specifically for use in formal or non-formal education;

- it is used as course-material in an educational course or program;

- it is included in a repository of materials intended to support formal/non-formal education".

Speaking about what can be considered an Open Educational Resources, Ischinger [2] include:

1. Learning content: full courses, courseware, content modules, learning objects, collections and journals.

2. Tools: software to support the development, use, reuse and delivery of learning content, including searching and organization of content, content and learning management systems, content development tools and learning communities, and

3. Implementation resources: intellectual property licenses to promote open publishing of materials, design principles of best practice and localize content.

Johnstone made a classification of three types of OERs [3], as:

- Learning resources and courseware, content modules, learning objects, learner-support and assessment tools, online learning communities;

- Resources to support teachers - tools for teachers and support materials to enable them to create, adapt and use OER;

- Resources to assure the quality of education and educational practices. 


\subsection{What are Open Licenses}

There is existing a non-profit organization named Creative Commons ,which has released several copyright-licenses known as Creative Commons licenses free of charge to the public. These licenses allow creators to communicate which rights them reserve, and which rights they waive for the benefit of recipients or other creator" [4]. For education, the idea that content should be free and openly available is one of the most important, because that means anyone will have access from all over the world at the educational content. The rights of using of different open content are expressed in the "5Rs Framework": retain, reuse, revise, remix, and redistribute. These permissions are granted to users free of charge, or with just a small amount of money.

In January 2016 there were an estimated 1.1 billion works licensed under the various Creative Commons licenses and that is speaking about the richness of the educational (not only) materials, which can be use in educational purposes.

\section{Why use OER}

The characteristics of the Millennials, which have been described by Howe and Strauss [5] and more recently of the Generation $\mathrm{Z}$ is speaking about individuals who [6]:

- have a strong relationship with technology as social environment;

- take into account change, the innovation being the pillars of their existence;

- believe it's cool to be smart;

- are fascinated by new technologies;

- are characterized by the idea that "if it has not been created, I can do it ".

The Children of these generations were the ones, who threw out the toys in favor of computers and devices and learned intuitively by themselves how to use them. So, we will not be surprised that, as highlighted by the current research Sparks \& Honey [7], children of the generation $\mathrm{Z}$ spend about $41 \%$ of their time outside school on the computer or on other devices, suffering from FOMO (fear of missing out ).

Especially for $Z$ Generation, the Internet and technologies have had a major influence on their culture and development. Millennials and Z Generation students have never known a world without computers, the World Wide Web, video games, cellular phones and other devices.

As researchers said [8], the brains of Generation $\mathrm{Z}$ are structurally different than those of earlier generations and this is not because of the genetics, but in connection we are using our brains to respond to things in our environment. Darla Rothman says the part of the brain which is responsible for visual ability is far more developed, making visual forms of learning more effective, while auditory learning (lecture and discussion) is very strongly disliked in Generation $Z$ case. The result is, said the researcher ,interactive games, collaborative projects, advance organizers, challenges, and anything that they can try and see are appreciated".

Other differences connected with this generation are:

- a very developed visual intelligence - they are able to understand, to read the images and to use the images for sending a message;

- a very developed spatial intelligence as a consequences of their playing video games from the earlier ages;

- the distributive attention which sometimes is called by teachers superficial;

- the ability to have fast responses in a short time and they need a quick response as well;

- the pleasure and the capacity to learn by doing, to learn from their discovery and not from the books or brochure. 
The conclusion about generation $\mathrm{Z}$ was they need to use collaborative work, to work in teams, to use experiential learning as part of their academic activities.

But the main focus for an effective and relevant educational process, in connection with Generation $\mathrm{Z}$ is the development of Knowledge society skills, with digital competence having both a leading and an enabling role. International reports such as 'Digital Education - Making the change happen' MCEETYA (2008); UNESCO ICT competence for teachers Hine, P. (2011), the on-line document from the 'Partnership for 21st century skills', European Commission Policy Report (2013): 'DIGCOMP: A Framework for Developing and Understanding Digital Competence in Europe' emphasize a developmental approach to bring about renovation of Education. In this process digital technologies and open educational resources serve as major catalysts in bringing about pedagogical innovation. Universities need to be changed from teaching institutions, driven by content-centered approaches, to learning institutions that use the context of curricular subjects to nurture knowledge society competences. The curricular content platform should be used to develop identified competences.

These reports recommend that Education should evolve along a three stage developmental trajectory. The initial Technology Literacy stage enables learners to use ICT to learn more efficiently. In the second Knowledge Deepening level learners acquire indepth knowledge of their school subjects and apply it to complex, real-world problems. The third level focuses on Knowledge Creation and serves to develop competences to create the new knowledge required for more harmonious, fulfilling and prosperous societies.

In this evolving process, the role of Digital Technologies and Open Educational Resources is to catalyze the much deserved pedagogical change from one focused on knowledge acquisition to one based on knowledge application and knowledge creation [9]. The current predominant teaching-centered approach should be complemented with truly student-centered approaches that employ digital technologies to mediate different modes of learning and assessment. Consequently the ability to identify, use, evaluate and create OER becomes a mandatory competence to be developed and refined throughout the educational process, and in particular with the professional development of teachers.

The perennial need for innovating teaching and learning practices brought about by the constant change in the nature and organization of knowledge, the continual emergence of new digital technologies and accompanying nascent behaviors, and the affinity of the younger generations with technology can only be mitigated by adopting a learning design attitude and approach that exploits the full potential of OER.

\section{OER in Engineering Education}

In Engineering Education and beyond the basic use for content acquisition, in the context of 21 st century education, OER are used to promote identified processes through which communication, different forms of learning, socialization, knowledge creation and sharing are nurtured. For example the ePortfolio open educational resource Mahara could be used, not just to showcase knowledge acquisition, but more important to promote autonomous learning, collaborative learning, individual and collective reflections and the nurturing of interactions within social networks. The different processes are the main outcomes of using the educational resource. The same principle can be applied to MOOCs in which interactive experiences beyond the acquisition of domain knowledge characterized the learning experience. Process-oriented pedagogical models, such as those proposed by Bonanno 2011 $\& 2015$, that organize learning and its assessment along different levels and dimensions of interactions, are more appropriate for using and evaluating OER. Consequently, OER can be categorized according to the pedagogical strategies they can mediate and according to the competences they can develop. 
The Framework for 21st Century skills describes how learning in core subjects and 21st century themes should not be the ultimate goal of the educational process, but more to provide the pedagogical context for developing 21 st century competences. Three major competence categories are identified: 'Life and Career skills', 'Learning and Innovation Skills' and 'Information, Media and Technology Skills'.

Life and Career skills are manifested through one's ability to navigate the complex life and work environments in the globally competitive information age requiring flexibility and adaptability, initiative and self-direction, social and cross-cultural skills, productivity and accountability, together with leadership and responsibility. Flexibility is manifested through one's ability to understand, negotiate and balance diverse views and beliefs to reach workable solutions, particularly in multi-cultural environments. One's ability to adapt to change is shown through one's adjustment to varied roles, jobs responsibilities, schedules and contexts.

Initiative and self-direction is shown through one's ability to manage goals, work independently and manage own learning. Social and cross-cultural skills are manifested by one's ability to interact effectively with others and work effectively in diverse teams. Productivity and accountability is shown by skills in managing projects and produce results. Leadership and responsibility involve skills for guiding and leading others and for being responsible to others.

The competence for Creativity and Innovation is manifested through critical thinking and problem solving and through communication and collaboration. One's creative and innovative potential is shown through creative thinking, creative collaboration and the ability to implement innovations. Critical thinking and problem solving involves one's ability to reason effectively, use systems thinking, make judgement, take decisions and solve problems. Communication and collaboration involves the ability to communicate clearly and to collaborate with others.

Information, Media and Technology competences are also described by this model through sub-categories of skills. Information literacy includes one's ability to 'access and evaluate information' and 'the ability to use and manage information'. Media literacy involves one's ability to analyze media and to create media products. ICT literacy is manifested through one's skill in applying digital technologies effectively as a tool to research, organize, evaluate and communicate information and to communicate and network with others. The Digicomp framework details the various aspects of digital competence by categorizing 21 competences into the following five major categories: Information, Communication, Content-creation, safety and problem-solving. Each of the competences is described in terms of knowledge, skills, and attitudes.

This competence framework offers the possibility to reflect about OER from a learning outcomes perspective. A resource is evaluated and defined by the type of competence or competences a user develops as a result of interacting with it. This user-centric approach is much more valid and relevant to designing and evaluating learning activities being driven by pedagogical principles and experience. Thus one way to evaluate OER is to consider the pedagogical principles and learning experiences they are capable to promote and support

There are many studies which present the importance of OER using in engineering education. As examples, there are Engineering textbooks along with additional material and a few lecture videos. Offered by professors from prestigious universities from America, Asia, Australia and, of course, Europe. As example, Dr. Kurt Gramoll from University of Oklahoma is offering an eCourse management system features content about Statics, Dynamic, Fluid Mechanics, Thermodynamics, Calculus, and Solid Mechanics [10].

In the same way, a huge number of universities are offering Open Educational Programs, in order to prepare future specialists in different fields. In a recent research about OER, realized in Erasmus + project called "EU-StORE- Creating European Standards for 
Open Educational Resources and Open Learning Resources" [11] in 2015, we found different universities from Europa, Asia and America, with very strong educational programs in Engineering education with a very high demand from the target group.

\section{Conclusion}

We can affirm, the number of OER applications in engineering education will continue to increase and to cover all the engineering domains.

An increasing number of the universities developed programs, libraries with textbooks collections, other supplementary materials, in order to help professors and students, or any potentials to conduct a course and to learn different subjects without costs, with a good connection and communication between students and instructor/professor. For students there will be a very easy way to learn from across multiple locations, platforms, or formats.

The development of OER and OER initiatives will facilitate the teaching process and will help teachers to be more adequate to the students' needs. And finally this will increase the learning motivation for the students.

\section{References}

1. A. Camilleri, U. Ehlers, J. Pawlowski, State of the Art Review of Quality Issues related to Open Educational Resources, retrieved from http://www.pedocs.de/volltexte/2014/9101/ (2014)

2. B. Ischinger, Giving Knowledge for Free: The Emergence of Open Educational Resources. (OECD, 2007)

3. S. M. Johnstone, Open Educational Resources Serve the World, Educause Quarterly 3 (2005).

4. https://creativecommons.org/, accessed in 09.02.2017

5. W. Strauss, N. Howe, Generations (Quill, New York, 1991)

6. C. S. Duse, D. M. Duse, The European Proceedings of Social \& Behavioural Sciences EpSBS (2016)

7. Sparks \& Honey at http://www.slideshare.net/sparksandhoney/generation-z-final-june17/8-They_are _mature_and_in, accessed in 24.10.2015

8. D. A. Rothman, Tsunami of Learners called Generation Z, available at http://www. mdle.net/Journal/A_Tsunami_of_Learners_Called_Generation_Z.pdf, accessed 6.06.2016

9. P. Bonanno, Ubiquitous Learning: A Survey of Applications, Research and Trends (2011)

10. http://guides.ou.edu/oer/engineering, accessed in 13.03.2016

11. http://eustore.eduproject.eu/, accessed in 16.09 .2016 